\title{
Microwave irradiated and conventional syntheses of halogenated symmetric double Schiff bases, their spectral and microbial study
}

\author{
Bhavesh J. Gangani ${ }^{1}$, Parsotam H. Parsania ${ }^{2^{*}}$ \\ ${ }^{1}$ Shree M. P. Shah Arts \& Science College, Surendranagar-363001, Gujarat, India \\ ${ }^{2}$ Department of Chemistry, Saurashtra University, Rajkot-360 005, Gujarat, India \\ 1,2E-mail address: bj2gangani@gmail.com, phparsania22@gmail.com
}

\begin{abstract}
Keywords: Halogenated Symmetric double Schiff base, Solvent free synthesis, Mass spectral fragmentation, Antimicrobial activity, MIC
\end{abstract}

\begin{abstract}
The aim of the present work was to discover various synthetic route of biological active halogenated symmetric double Schiff bases of 1,1'-bis(4-aminophenyl)cyclohexane, their spectral and microbial study. Symmetric double Schiff base ligands of halogenated benzaldehyde and 1,1'-bis(4-aminophenyl)cyclohexane were synthesized by conventional and green chemistry approach. The purity of Schiff bases was checked by Thin Layer Chromatography (TLC). The structures of these ligands were elucidated by UV, FTIR, ${ }^{1} \mathrm{HNMR}$ and MS; and assayed for their antibacterial activity against Escherichia coli (E. coli), Bacillus megaterium (B.mega), Proteus vulgaris (P. vulgaris, Staphylococcus aureus (S. aureus) and Aspergillus niger (A. niger)The minimum inhibition concentrations (MIC) of the compounds were studied by cup plate method. Schiff bases revealed moderate antimicrobial activity and good antifungal activity against chosen standard drugs and microorganisms.
\end{abstract}

\section{INTRODUCTION}

Schiff bases or imines or azomethines are condensation products of aromatic primary amines with aromatic aldehydes or ketones have played a vital role in the progress of chemical sciences [1]. Schiff bases are organic compounds used as pigments and dyes, catalysts, intermediates in organic synthesis [2, 3]. Schiff bases continue to occupy an important position as fine chemicals, medical substrates and ligands for metal complexes having industrial importance as an asymmetric catalysis [4-6]. Schiff bases have wide applications in food industries, dye industries, in analytical chemistry, as a fungicide in agro chemical [7, 8]. Schiff bases have been known to possess huge variety of biological importance like antibacterial, antifungal, antiviral, antiinflammatory and antiparasitic [9-10]. They are also useful as starting materials for the synthesis of drugs like antibiotics, antidepressant, antiallergic, antiphlogistic and antitumor [11-13]. Kuzmin et. al have reported anticancer activity of a set of macro cyclic Schiff bases based on 2,6-bis(2 and 4 formyl arylosy methyl) pyridines[14]. Lozitsky et. al have reported 4D-QSAR study and anticancer activity of Schiff bases synthesized by the condensation of various aliphatic and aromatic diamines with 2,6-bis(2 and 4 formyl arylosy methyl) pyridine derivatives [15].

Schiff base of o-phenylene diamine and its complex have clinical application [16]. It has been found that Schiff bases are potential anticancer drug and anticancer activity increased when it used in the form of complexes as compared to free ligands [17]. A number of previous studies proposed that Schiff bases of diamines and aromatic aldehydes displayed effective antimicrobial and selective antitumor activity [18, 19]. Mondal et.al [20] has reported synthesis of 3-ethoxy salicylaldehyde diamine ligands. Qin et al. [21] reported Schiff base as reactants in umpteen synthetic organic processes, as important scaffolds in organo metallic chemistry, as backbones of precious catalysts and as pharmaceutical presidiums against a series of different diseases and pathological states. According to their review simple headline is not possible to account the multidisciplinary applications of Schiff Bases.

Microwave-assisted synthesis is a branch of green chemistry. The application of microwaveassisted synthesis in organic, organo metallic and coordination chemistry are in continuous 
development. Jain et al. [22] have synthesized tridentate Schiff bases and their metal complexes by microwave irradiation and studied their thermal, spectral and antimicrobial properties. Ajani et al. [23] discovered that microwave-assisted approach is highly efficient procedure for the preparation of various $2(1 H)$-quinoxalinone-3-hydrazone derivatives compared to conventional heating method. The reactions occurred remarkably fast, under mild condition using highly inexpensive reagents and a domestic microwave oven as the irradiation source. The benefits of this environmentally benign and safe protocol include a simple reaction set-up, application of commercially available inexpensive reagents, easy work-up, high product yields, short reaction time as well as the easy elimination of solvents. Thus, this work will be very useful for further studies in terms of toxicity effect and Structure Activity Relationship (SAR) to improve their biological and pharmacological activities. They have synthesized heterocyclic compounds by conventional and microwave irradiation methods and compared theirs data.

In view of these application of bis-Schiff bases and in continuation of our investigations [24], here we report the green synthetic approach towards synthesis of biologically active compounds including conventional synthesis, spectral and microbial characterization of a new class of halogenated bis-Schiff bases by the reaction between halogen substituted aromatic benzaldehydes and 1, 1'-bis (4-aminophenyl)cyclohexane.

\section{MATERIALS AND METHODS}

Solvents and chemicals used in the present investigation were purchased from Allied Chemicals (Vadodara) of LR grades and used either as such or purified by fractional distillation. Reactions were monitored by thin layer chromatography (TLC) on pre-coated silica gel GF254 plates (E-Merck Co) by using appropriate solvent systems. Melting points were determined in open capillary tubes and were uncorrected. UV spectra were scanned on a Shimadzu UV-1700 spectrophotometer by using $\mathrm{CHCl}_{3}$ and DMSO as solvents. IR spectra ( $\mathrm{KBr}$ pellets) were scanned on a Shimadzu FTIR- 8400 spectrometer. The NMR spectra of Schiff bases were scanned on a Brucker FTNMR (300 MHz) spectrometer by using $\mathrm{CDCl}_{3}$ as a solvent and TMS as an internal standard. Mass spectra of the compounds were scanned on a Shimadzu GC-MS-QP 2010 spectrometer by using EI $(0.7 \mathrm{kV})$ detector. The ion source temperature was $220^{\circ} \mathrm{C}$ and interface temperature was $240^{\circ} \mathrm{C}$. Microbial activity of the compounds was checked by cup-plate technique [25].

\section{SYNTHESIS}

Synthesis of 1, 1'-bis (4-aminophenyl)cyclohexane was synthesized by acid catalyzed condensation of aniline hydrochloride and cyclohexanone (Scheme 1) and crystallized according to our work [24].

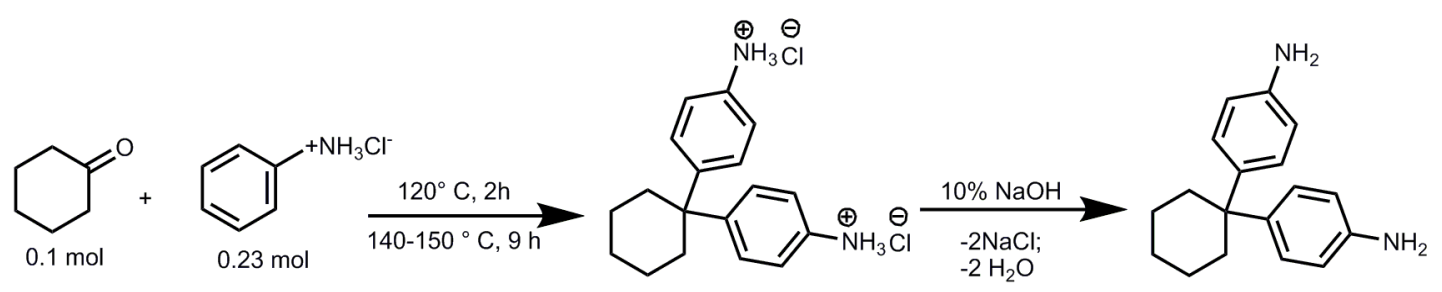

Scheme 1 Synthesis of 1, 1' bis (4-aminophenyl)cyclohexane 


\subsection{Synthesis of halogenated symmetric Schiff bases by conventional method}

A solution of 0.01 mole 1, 1'- bis (4-aminophenyl)cyclohexane was prepared in $25 \mathrm{ml}$ ethanol and taken into a $100 \mathrm{ml}$ round bottomed flask fitted with reflux condenser. To this solution $2 \mathrm{ml}$ of glacial acetic acid was added as a catalyst and allowed warming solution in a water bath. To this solution 0.021 mole of halogenated benzaldehyde in $15 \mathrm{ml}$ ethanol was added drop wise and then refluxed for 0.5 - $3 \mathrm{~h}$ (Table 1). The product was isolated from chilled water, filtered, washed well with sodium bisulfite, water and finally with ethanol and dried at $50^{\circ} \mathrm{C}$ in an oven. The Schiff bases are soluble in common solvents like $\mathrm{CHCl}_{3}, \mathrm{CCl}_{4}$, benzene, THF, 1,4-dioxane, DMF, DMSO, etc. The Schiff bases were crystallized from appropriate solvent systems (Table 1). The purity was checked by TLC. Solvent system for TLC along with physical and analytical data of Schiff bases are reported in Table1, while reaction time and yields are reported in Table 2.
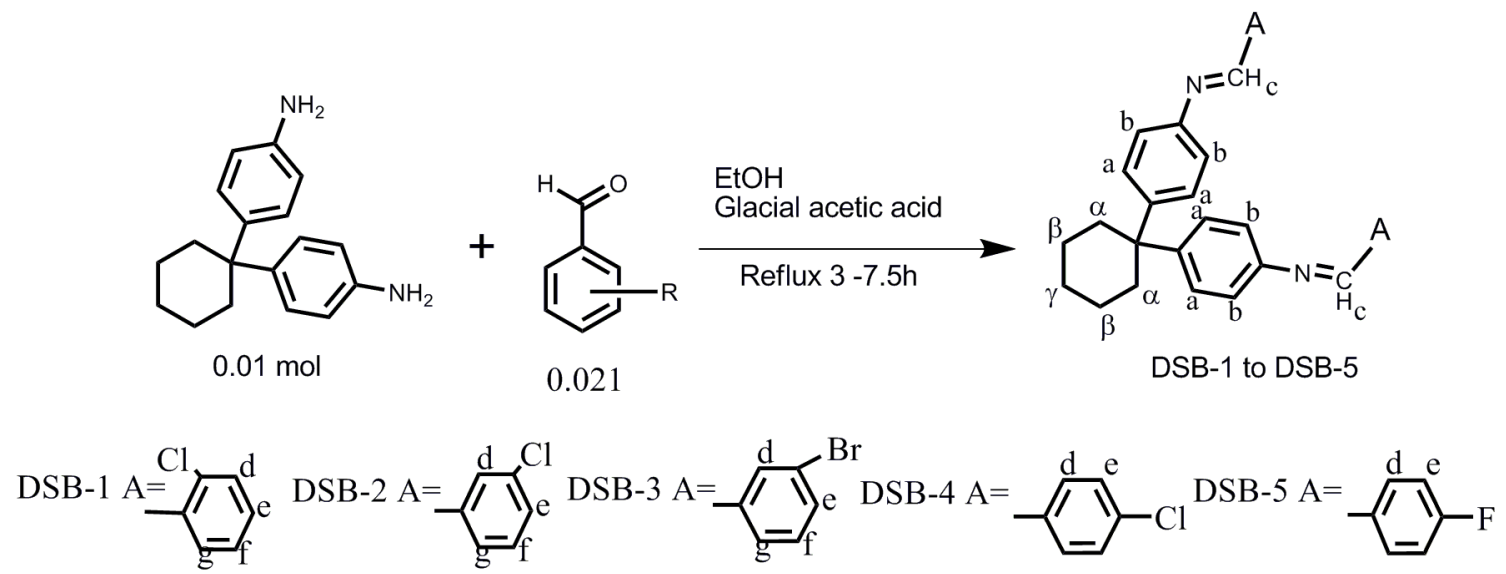

Scheme 2 Syntheses of halogenated symmetric double Schiff bases

Table 1 Physical and analytical data of DSB-1 to DSB-5

\begin{tabular}{|c|c|c|c|c|c|c|c|}
\hline \multirow{2}{*}{ Code } & \multirow{2}{*}{ MF } & \multirow{2}{*}{ M W } & \multirow{2}{*}{$\underset{{ }^{0} \mathbf{C}}{\mathbf{m}} \mathbf{p}$} & \multirow{2}{*}{ Color } & \multirow{2}{*}{$\begin{array}{c}\text { Crystal. } \\
\text { solvent } \\
\text { system }\end{array}$} & \multicolumn{2}{|l|}{ TLC } \\
\hline & & & & & & Solvent system & $\begin{array}{c}\mathbf{R}_{\mathbf{f}} \\
\text { value }\end{array}$ \\
\hline DSB -1 & $\mathrm{C}_{32} \mathrm{H}_{28} \mathrm{~N}_{2} \mathrm{Cl}_{2}$ & 511 & 233 & Off white & $\mathrm{CF}-\mathrm{H}$ & $\mathrm{EA}-\mathrm{H}(80: 20 \mathrm{~V} / \mathrm{V})$ & 0.63 \\
\hline DSB -2 & $\mathrm{C}_{32} \mathrm{H}_{28} \mathrm{~N}_{2} \mathrm{Cl}_{2}$ & 511 & 232 & Off white & EA-H & EA- H $(60: 40 \mathrm{~V} / \mathrm{V})$ & 0.72 \\
\hline DSB -3 & $\mathrm{C}_{32} \mathrm{H}_{28} \mathrm{~N}_{2} \mathrm{Cl}_{2}$ & 511 & 228 & Off white & EA-H & EA- H $(60: 40 \mathrm{~V} / \mathrm{V})$ & 0.74 \\
\hline DSB -4 & $\mathrm{C}_{32} \mathrm{H}_{28} \mathrm{~N}_{2} \mathrm{Br}_{2}$ & 600 & 268 & Yellow & B -H & $\mathrm{CF}-\mathrm{H}(70: 30 \mathrm{~V} / \mathrm{V})$ & 0.64 \\
\hline DSB -5 & $\mathrm{C}_{32} \mathrm{H}_{28} \mathrm{~N}_{2} \mathrm{~F}_{2}$ & 478 & 224 & Light brown & $\mathrm{CF}$ & $\mathrm{CF}-\mathrm{H}(80: 20 \mathrm{~V} / \mathrm{V})$ & 0.59 \\
\hline
\end{tabular}

CF: Chloroform, EA: Ethylacetate, B: Benzene, $\mathrm{H}=$ n-Hexane 
Table 2 Conventional and microwave irradiated reaction times and \% yields of DSB-1 to DSB-5

\begin{tabular}{|c|c|c|c|c|}
\hline Code & \multicolumn{2}{|c|}{ Classical method } & \multicolumn{2}{c|}{ Microwave irradiation } \\
\hline & Time, $\mathbf{h}$ & \% Yield & Time, min & \% Yield \\
\hline DSB -1 & 0.75 & 78 & 3 & 91 \\
\hline DSB -2 & 0.75 & 75 & 3 & 92 \\
\hline DSB - 3 & 0.50 & 70 & 3 & 90 \\
\hline DSB -4 & 2.00 & 69 & 6 & 93 \\
\hline DSB -5 & 3.00 & 78 & 6 & 88 \\
\hline
\end{tabular}

\subsection{Syntheses of halogenated symmetric Schiff bases by green chemistry approach}

Due to environmental friendly, economic, rapid reaction rate and less use of hazardous chemicals [26], solvent free synthesis of halogenated symmetric double Schiff bases was carried out in a

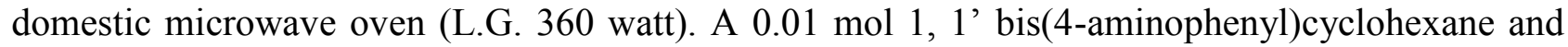
$0.021 \mathrm{~mol}$ halogenated benzaldehyde were mixed together at ambient temperature in a $50 \mathrm{ml}$ Erlenmeyer flask. The mixture was subjected to microwaves for an optimized time. The progress of the reaction was monitored by simultaneous TLC in appropriate solvent systems and purity was checked by TLC. The yield and time required for conventional and green chemistry approach are reported in Table 2.

\section{RESULTS AND DISCUSSION}

Five new halogenated symmetric double Schiff bases were synthesized by conventional and microwave irradiated methods. In conventional organic synthesis reaction mixture are heated using an external heat source and therefore heat transferred through conductance. This is comparatively slow and inefficient method for transferring energy into the system because it depends on thermal conductivity of the various materials that must be penetrated and result in increasing temperature of reaction vessel being higher than that of a reaction mixture. By opposite to it microwave irradiation produces efficient internal heating by direct coupling of microwave energy with polar molecules [27-29]. Thus Green chemistry approach found more rapid, economic and gave better yields as compared to conventional approach for halogenated symmetric double Schiff bases data are reported in Table 2.

\subsection{Characterization of the Schiff bases}

DSB-1: UV $\left(\lambda_{\max }, \mathrm{nm}\right): 266.0\left(\mathrm{CHCl}_{3}\right), 267.4$ (DMSO), IR $\left(\mathrm{KBr} \mathrm{cm}^{-1}\right): 2941.5$ and $2859.3(\mathrm{C}-\mathrm{H}$ str.), 1626.8 (-CH=N str.), 1591.2 and 1565.2 ( $\mathrm{Ar} \mathrm{C}=\mathrm{C}$ str.), 1306.7 (C-N str.), 1173.6 and 1151.4 (C-H ipd), 836.1 (C-H oopd), ${ }^{1} \mathrm{H}$ NMR $\left(\mathrm{CdCl}_{3}, \mathrm{ppm}\right): 1.547\left(6 \mathrm{H}, \mathrm{s}, \beta+\gamma,-\mathrm{CH}_{2}-\right), 2.246(4 \mathrm{H}, \mathrm{s}, \alpha,-$

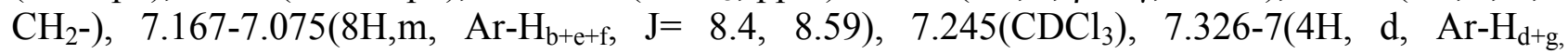
$\mathrm{J}=8.54), 7.894-7.847\left(4 \mathrm{H}, \mathrm{m}, \mathrm{Ar}-\mathrm{H}_{\mathrm{a}}, \mathrm{J}=5.6\right.$ and 6.77$), 8.477\left(2 \mathrm{H}_{\mathrm{c}}, \mathrm{s},-\mathrm{CH}=\mathrm{N}-\right), \mathrm{MS}(\mathrm{m} / \mathrm{z}): 511$.

DSB-2: UV $\left(\lambda_{\max } \mathrm{nm}\right): 265.0\left(\mathrm{CHCl}_{3}\right), 266.8$ (DMSO), IR $\left(\mathrm{KBr} \mathrm{cm}^{-1}\right): 2929.7$ and $2854.5 \mathrm{C}-\mathrm{H}$ str. $)$, 1622.0(-CH=N str.), 1598.9 and 1499.6 (Ar C=C str.), 1358.8(C-N str.), 1173.6 and $1072.3(\mathrm{C}-\mathrm{H}$ ipd), 894.9 (C-H oopd), MS(m/z): 511.

DSB-3: UV ( $\left.\lambda_{\text {max }}, \mathrm{nm}\right): 245.4\left(\mathrm{CHCl}_{3}\right), 266$ (DMSO), IR ( $\left.\mathrm{KBr} \mathrm{cm}^{-1}\right): 2935.5$ and 2860.2(C-H str.), 1627.8( $-\mathrm{CH}=\mathrm{N}$ str.), 1353.9(C-N str.), 1606.6 and 1552.6 ( $\mathrm{Ar} \mathrm{C}=\mathrm{C}$ str.), $1353.9(\mathrm{C}-\mathrm{N}$ str.), 1168.8 and 1123.5 (C-H ipd), 815.8 (C-H oopd), ${ }^{1} \mathrm{H}$ NMR $\left(\mathrm{CdCl}_{3}, \mathrm{ppm}\right): 1.575\left(6 \mathrm{H} \mathrm{s}, \beta+\gamma,-\mathrm{CH}_{2-}\right), 2.296$ $\left(4 \mathrm{H} \mathrm{s}, \alpha-\mathrm{CH}_{2}-\right), 7.151-7.122\left(4 \mathrm{H}, \mathrm{d}, \mathrm{Ar}-\mathrm{H}_{\mathrm{b}}, \mathrm{J}=8.7\right), 7.238\left(\mathrm{CDCl}_{3}\right), 7.322-7.294\left(4 \mathrm{H}, \mathrm{d}, \mathrm{Ar}-\mathrm{H}_{\mathrm{d}}\right.$, $\mathrm{J}=8.4), 7.477-7.389\left(4 \mathrm{H}, \mathrm{d}, \mathrm{Ar}-\mathrm{H}_{\mathrm{e}}, \mathrm{J}=8.4\right), 7.806-7.777\left(4 \mathrm{H}_{\mathrm{c}}, \mathrm{d}, \operatorname{Ar}-\mathrm{H}_{\mathrm{a}}, \mathrm{J}=8.3\right), 8.389(2 \mathrm{H}, \mathrm{s}$, $-\mathrm{CH}=\mathrm{N}-), \mathrm{MS}(\mathrm{m} / \mathrm{z}): 511$. 
DSB-4:UV $\left(\lambda_{\text {max }}, \mathrm{nm}\right): 265.2\left(\mathrm{CHCl}_{3}\right), 268.8$ (DMSO), IR $\left(\mathrm{KBr} \mathrm{cm}^{-1}\right): 2929.7$ and $2854.5(\mathrm{C}-\mathrm{H}$ str. $)$, 1622.5(-CH=N str.), 1598.9 and 1497.6 (Ar C=C str.), 1357.8 (C-N str.), 1172.6 and 1064.3 (C-H ipd) 883.3 (C-H oopd), ${ }^{1} \mathrm{H}$ NMR ( $\left.\mathrm{CDCl}_{3}, \mathrm{ppm}\right): 1.583\left(6 \mathrm{H}, \mathrm{s}, \beta+\gamma,-\mathrm{CH}_{2}-\right), 2.306\left(4 \mathrm{H}, \mathrm{s}, \alpha,-\mathrm{CH}_{2^{-}}\right)$ 7.169-7.130 (4H,d, Ar- $\left.\mathrm{H}_{\mathrm{b}}, \mathrm{J}=8.5\right), 7.244\left(\mathrm{CDCl}_{3}\right), 7.333-7.280\left(6 \mathrm{H}, \mathrm{t}, \mathrm{Ar}-\mathrm{H}_{\mathrm{a}+\mathrm{f}}, \mathrm{J}=7.5\right.$ and 8.3$)$ 7.679-7.652 (2H, d, Ar- $\mathrm{H}_{\mathrm{f}}, \mathrm{J}=8.1$ ).7.764-7.738 (2H, d, Ar- $\left.\mathrm{H}_{\mathrm{g}}, \mathrm{J}=7.8\right) 8.060\left(2 \mathrm{H}, \mathrm{s}, \mathrm{Ar}-\mathrm{H}_{\mathrm{d}},\right), 8.397$ $\left(2 \mathrm{H}_{\mathrm{c}}, \mathrm{s},-\mathrm{CH}=\mathrm{N}-\right), \mathrm{MS}(\mathrm{m} / \mathrm{z}): 600$.

DSB-5: UV $\left(\lambda\right.$ max, nm): $265.4\left(\mathrm{CHCl}_{3}\right), 266$ DMSO, IR $\left(\mathrm{KBr} \mathrm{cm}^{-1}\right): 2941.2$ and 2860, 1626.8 $(\mathrm{CH}=\mathrm{N}$ str. $), 1591.2$ and 1507.3 (Ar $\mathrm{C}=\mathrm{C}$ str.), 1351.0(C-N), 1173.6,1150.5 (C-H ipd), $836.1(\mathrm{C}-\mathrm{H}$ oopd), ${ }^{1} \mathrm{H}$ NMR $\left(\mathrm{CDCl}_{3}, \mathrm{ppm}\right): 1.591\left(6 \mathrm{H}, \mathrm{s}, \beta+\gamma,-\mathrm{CH}_{2}-\right), 2.304\left(4 \mathrm{H}, \mathrm{s}, \alpha,-\mathrm{CH}_{2}-\right), 7.156-7.098$ $\left(8 \mathrm{H}, \mathrm{m}, \mathrm{Ar}-\mathrm{H}_{\mathrm{b}+\mathrm{d}} \mathrm{J}=8.7\right.$ ), 7.334-7.299(4H,d,Ar-H $\left.\mathrm{a}, \mathrm{J}=8.5\right), 7.899-7.834\left(4 \mathrm{H}, \mathrm{m}, \mathrm{Ar}-\mathrm{H}_{\mathrm{e}}, \mathrm{J}=8.1\right), 8.405$ $\left(2 \mathrm{H}_{\mathrm{c}}, \mathrm{s},-\mathrm{CH}=\mathrm{N}-\right), \mathrm{MS}(\mathrm{m} / \mathrm{z}): 478$.

\subsection{IR spectral analysis}

In the IR spectra, all the compounds displayed the characteristic peak in the region $1614-1629 \mathrm{~cm}^{-1}$ indicated the formation of Schiff bases $(-\mathrm{H}-\mathrm{C}=\mathrm{N})$ [30]. The IR spectra of DSB -1 , DSB -2 and DSB -3 exhibited a sharp bands at $629.7,652.9$ and $609.5 \mathrm{~cm}^{-1}$ due to presence of $\mathrm{C}-\mathrm{Cl}$ stretching, while DSB -4 and DSB -5 exhibited C-Br and C-F stretching at $682.8 \mathrm{~cm}^{-1}$ and $1093.6 \mathrm{~cm}^{-1}$, respectively. All Schiff bases showed C-H symmetric and asymmetric absorption bands due to $\mathrm{CH}_{2}$ groups in the range of 2939-2925 $\mathrm{cm}^{-1}$ and 2860-2843 $\mathrm{cm}^{-1}$, while C-H scissoring and C-H twisting bands are observed in the range of $1480-1440 \mathrm{~cm}^{-1}$ and $1250 \mathrm{~cm}^{-1}$. Vibration bands due to $\mathrm{CH}=\mathrm{N}, \mathrm{C}=\mathrm{C}$, and $\mathrm{C}-\mathrm{N}$ are observed in the range of $1630-1617,1602-1581$, and $1364-1307 \mathrm{~cm}^{-1}$, respectively. C-H out of plane deformation for aromatic 1,4-disubstitution is observed in the range of $827-811 \mathrm{~cm}^{-1}$, while C-H in plane deformation is observed in the range of $1288-1011 \mathrm{~cm}^{-1}$ for all Schiff bases.

\section{3 ${ }^{1}$ HNMR spectral analysis}

The structure characterization further supported by their ${ }^{1}$ HNMR spectra, The most important peak in the Schiff base ligand was attributed to a singlet signal due to azomethine proton in a range of 8.38 to $8.52 \mathrm{ppm}$ that confirmed the formation of Schiff base [31]. The integrated areas under the NMR peaks are observed in accordance to number of expected protons. The peak due to $\mathrm{CDCl}_{3}$ appeared at about 7.25-7.24 ppm either as a separate peak or overlapped with peaks due to aromatic protons.

\subsection{Electronic spectra}

UV spectroscopic studies of Schiff bases in polar and nonpolar solvents have reported by several scientists [32-33]. In order to understand the effect of medium on absorption of maximum wavelength $\left(\lambda_{\max }\right)$ was studied in two different solvents namely $\mathrm{CHCl}_{3}$ and DMSO. It is observed that nonpolar or less polar solvents have least interaction with the molecule under investigation. But the position and intensity of absorption maxima is shifted towards bathochromic shift for a halogen group by using more polar solvent. The value of $\lambda_{\max }$ for Schiff bases in $\mathrm{CHCl}_{3}$ and DMSO are reported in characterization from which it is clear that DMSO solutions showed blue shift. In electronic spectra of Schiff base stronger and higher peak was attributed to the $\prod \rightarrow \prod^{*}$ transition of the azomethine, chromophore and the benzene ring, while the weaker and less energetic peak is assigned to the $n \rightarrow \prod^{*}$ transition involving the promotion of the lone pair of electron of azomethine nitrogen atom into the antibonding $\pi$ orbital associated with azomethine group [34].

\subsection{Mass spectral analysis}

The molecular ion, (though it may be law abundance) gives highly useful information about the identity of an organic compound. Fragmentation pattern, i.e., the break-up process of the molecular ion into small ions (fragments or daughter ions) gives further information about the structure of the compound. All fragment ions are, however, not of equal significance to assign the structure of a compound. The mechanism of mass fragmentation is shown in Scheme 3. The molecular ion peaks $\mathrm{M}^{+},(\mathrm{M}-1)^{+}$and some of the main fragments are reported in Table 3. 
Table 3 Molecular ion $\left(\mathrm{M}^{+}\right)$, $(\mathrm{M}-1)^{+}$peaks and some important Fragments of DSB-1 to DSB- 5.

\begin{tabular}{|c|c|c|c|c|c|c|c|c|c|}
\hline $\begin{array}{c}\text { Schiff } \\
\text { base }\end{array}$ & $\mathbf{M}^{+}$ & $\left.\mathbf{~}^{\text {M-1 }}\right)^{+}$ & F-1 & F-2 & F-3 & F-4 & F-5 & F-6 & F-7 \\
\hline DSB -1 & 511 & 510 & 469 & 139 & 372 & 330 & 91 & 77 & 178 \\
\hline DSB -2 & 511 & 510 & 468 & 139 & 372 & 329 & 91 & 77 & 178 \\
\hline DSB-3 & 511 & 510 & 468 & 139 & 372 & 329 & 91 & 77 & 178 \\
\hline DSB -4 & 600 & 599 & 558 & 183 & 417 & 375 & 91 & 77 & 178 \\
\hline DSB -5 & 478 & 477 & 436 & 122 & 356 & 314 & 91 & 77 & 178 \\
\hline
\end{tabular}

Table 4 A comparative zone of inhibition for standard drugs and Schiff bases

\begin{tabular}{|c|c|c|c|c|c|}
\hline Sample & $\begin{array}{c}\text { E. coli } \\
\text { MTCC-443, }\end{array}$ & $\begin{array}{c}\text { B. mega } \\
\text { MTCC-244 }\end{array}$ & $\begin{array}{c}\text { B. sub. } \\
\text { MTCC-441 }\end{array}$ & $\begin{array}{c}\text { P. vulgaris } \\
\text { MTCC-744 }\end{array}$ & $\begin{array}{c}\text { A. niger } \\
\text { MTCC-282 }\end{array}$ \\
\hline DSB-1 & 11 & 10 & 12 & 9 & 16 \\
\hline DSB -2 & 10 & 10 & 12 & 11 & 17 \\
\hline DSB -3 & 11 & 10 & 12 & 11 & 16 \\
\hline DSB -4 & 12 & 9 & 11 & 10 & 15 \\
\hline DSB -5 & 8 & 9 & 10 & 9 & 14 \\
\hline Ampicillin & 18 & 19 & 22 & 22 & 18 \\
\hline Amoxicillin & 17 & 21 & 19 & 23 & - \\
\hline Ciprofloxacin & 22 & 20 & 21 & 24 & - \\
\hline Erythromycin & - & - & - & - & 18 \\
\hline
\end{tabular}

\section{ANTIMICROBIAL ACTIVITY}

The antibacterial and antifungal activities of halogenated symmetric double Schiff base ligands DSB-1 to DSB- 5 were screened against various microorganisms using standard drugs such as amoxicillin, ampicillin, ciprofloxacin and erythromycin. DMF was used as a solvent. The microorganisms used in present investigation were Escherichia coli (E. coli), Bacillus megaterium (B. mega), Proteus vulgaris (P. vulgaris), and A spergillus niger (A. niger). The activity was tested by cup plate method at $37^{\circ} \mathrm{C}$. The cup plate method is very simple. It requires petri disks; the medium used was Mueller-Hinton agar with $2 \%$ of glucose. The plates were incubated for $24 \mathrm{~h}$ at $37^{\circ} \mathrm{C}$ and zones of inhibition for each microbial growth were measured relative to control DMF. The microbial activity was estimated on the basis of the zone of inhibition [25]. The sample volume was $0.1 \mathrm{ml}(50 \mu \mathrm{g})$. A comparative zone of inhibition $(\mathrm{mm})$ for Schiff bases and standard drugs are reported in Table 4, from which it is clear that DSB-1 to DSB-5 showed moderate antibacterial activity in comparison with standard drugs. Chlorine substituted Schiff bases showed good antifungal activity as compared to bromine and fluorine containing compounds. 


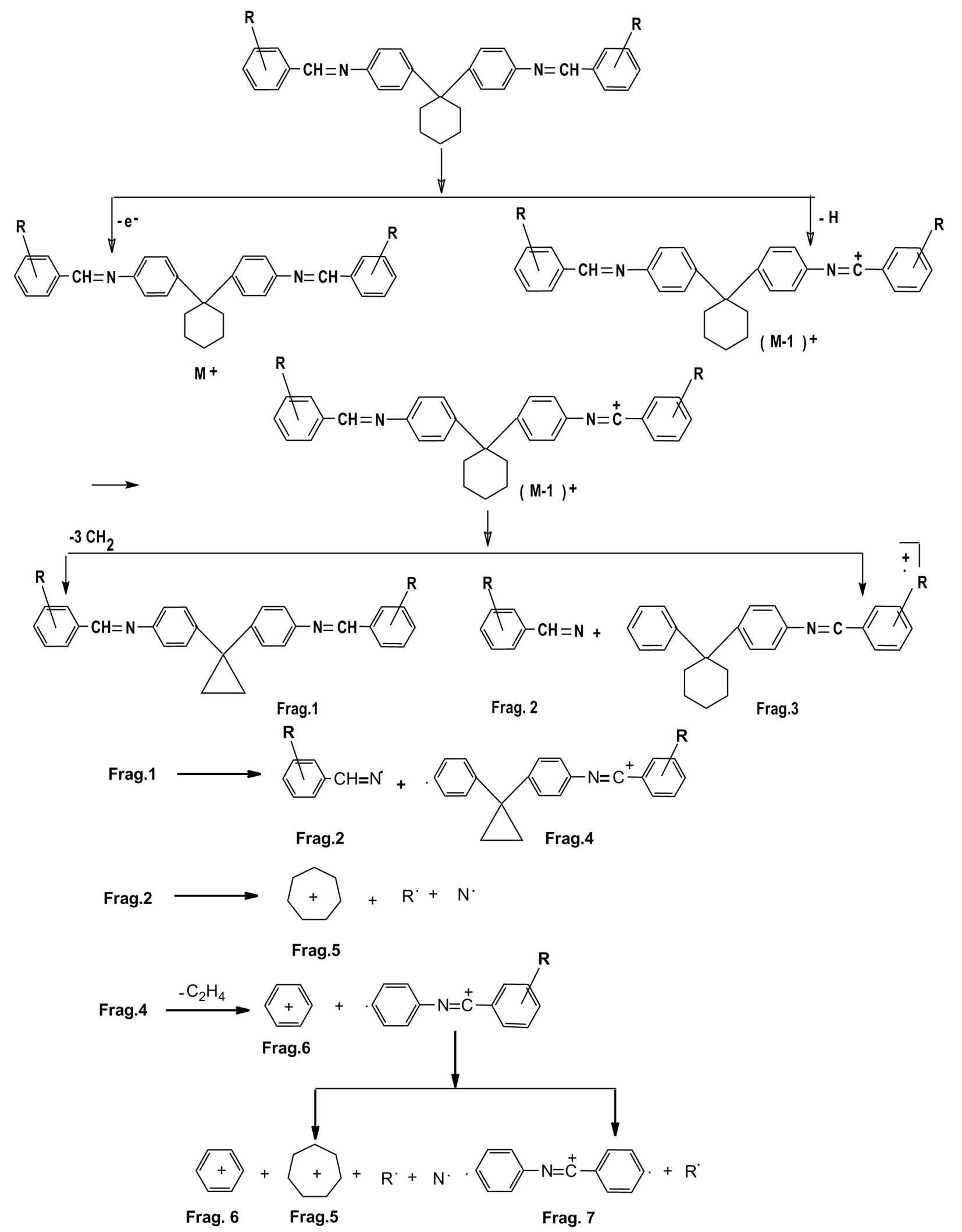

Scheme 3 Mass spectra fragmentation of DSB-1 to DSB-5 


\section{CONCLUSIONS}

1 On the basis of experimental findings it is concluded that the reaction time is shortened from 0.5-3h to 5-9 min and reaction yield is improved from $69-80 \%$ to $80-89 \%$ with the use of microwave irradiation solvent free condensation.

2 Spectral data supported expected structure of the compounds.

3 DSB-1 to DSB -5 showed moderate antibacterial activity and comparable antifungal activity in comparison with chosen standard drugs. Schiff base ligands containing chlorine substituent showed moderate antibacterial activity and good antifungal activity as compared to chosen standard drugs.

4 The class of bis-Schiff bases may be used as templates for generating better lead molecules to fight against bacterial and fungal strains.

\section{Acknowledgments}

The authors are thankful the Director SAIF, Punjab University, Chandigarh for NMR analysis, UGC-New Delhi and DST-New Delhi for instrumentation support grants.

\section{References}

[1] S. Patai The chemistry of the carbon-nitrogen double bond. (John-Wiley and Sons. Ltd. London (1970)

[2] D. N. Dhar, C. N. Taploo, J Sci. Ind. Res., 41(8) (1982) 501-506.

[3] R.W. Layer, Chem Rev., 63 (1963) 487-507.

[4] A. P. Mishra, M. Khare, S. K. Gautam, Synth. React Inorg. Met-Org Chem., 32(2002)14851500 .

[5] C .Bi, Y. Fan, Synth. React Inorg and Met-Org Chem. 34 (2004) 687-695.

[6] S. Matsunaga, M. Shibasaki, Chem. Commun. 50(2014) 1044-1057.

[7] A. Prakash, D. Adhikari, Int. J. Chem. Tech. Research. 3(4) (2011) 1891-1896.

[8] S. H. Abdel-Hafez, Phosphorus, sulfur, and silicon. 178(2003) 2563-2579.

[9] N.B. Patel, J.C. Patel, Arabian J Chem. 4 (2011) 403-411.

[10]P. Panneerselvam, B. A. Rather, D. R. Reddy, N. R. Kumar, Euro. J. Med. Chem. 44, 23282333(2009).

[11]K. D. Patel, B. D. Mistry, K. R. Desai, J. Ind. Chem. Soc., 81(2004) 783-785.

[12] M. M. Kamel, H. L. Ali, M. M. Anawar, N. A. Mohamed, A. M. Soliman, Euro. J. Med. Chem. 45 (2010)572-580.

[13] V. E. Kuzmin, V. P. Lozitsky, G. L. Kamalov, R. N. Lozitskaya, A. I. Zheltvay, A. S. Fedtchouk, D. N. Kryzhanovsky, Acta Biochimica, Polonica, 47(2000)867-875.

[14] V. P. Lozitsky, V. E. Kuzmin, A. G. Artemenko, R. N. Lozytska, A. S. Fedtchouk., E. N. Muratov, A. K. Mescheriakov, SAR and QSAR in Environmental Research, 16(2005) 219-230.

[15]A. M. Mohindru, J. M. Fisher, M. Rabinovitz, Nature, 303(1983) 64-65

[16]R. Tundor, N. Maria, P. Simona, P. Elena, P. Donald, G. Aurelina, Euro. J. Med. Chem., 45(2) (2010)774-781.

[17] A.T. Shinde, S.B. Zangade, S.B. Chavan, Y.B. Vibhute Am. J. Pharmtech. Res., 2(2011)43-48

[18]A. B. Begum, N.D. Rekha, B.C Vasanthakumar, V. L. Ranganatha, S. A. Khanum, Bioorg. Med. Chem. Lett. DOI 10.1016/ j.bmcl.2014.05.046.

[19] S. Mondal, M. Nayak, H. Sparkes, J. Howar, S. Mohanta, J. Coord. Chem., 67(2014)72-80.

[20]W. Qin, S. Long, M. Panunzio, S. Biondi, Molecules. 18(2013) 12264-12289.

[21]R. K. Jain, A. P. Mishra, J. Serb. Chem. Soc., 77 (8) (2012)1013-1029.

[22] O. O. Ajani, C. A. Obafemi, C. O. Ikpo1, K. O. Ajanaku, K. O. Ogunniran, O. O. James, Int. J. Physical. Sci., 4 (4) (2009) 156-164.

[23] B. J. Gangani, P. H. Parsania, Spectroscopy Letters 40(2007) 97-112. 
[24] A. L. Bary, The antimicrobial susceptibility test, principle and practice, $180-193$ (Philadelphia, 1976)

[25] M. Yadav, N. Mishra, N. Sharma, S. Chandra, D. Kumar, Spectrochimica Acta Part A: Molecular and Biomolecular Spectroscopy 132(2014) 733-742.

[26] N. K. Jain, Progress in control Release Drug delivery system. 470-491(CBS Publication, New Delhi, 2004)

[27]J. B. Schwartz, Optimization techniques in pharmaceutical formulation and processing in Banker, $4^{\text {th }}$ Ed., 803-828(Modern pharmaceutics, Marcel Dekker, New York, 2000)

[28] J. Panda, V. J. Patro, B. M. Sahoo, J. Mishra, J. of Nanomaterials, Article ID 549502 (2013)

[29]A. Esteves-Souze, K. Pissinate, M. Grac, N. Noem, F. Grynberg, A. Echevarria, Bio. Org. Med. Chem. 14(2006) 492-499.

[30]B. Shafaatian, A. Soleymanpour, N. K. Oskouei, B. Notash, S.A.Rezvani, Spectrochimica Acta Part A: Molecular and Biomolecular Spectroscopy 128(2014) 363-369.

[31] C. A. Sandorfy, J. W. Lewis, Can. J. Chem. 60(13) (1982)1727-1737.

[32]M. Yildiz, Z. Kilic, T. Hokelek, Mol. Struct. 441(1998) 1-10.

[33]B. Bonish, J. Am. Chem. Soc. 90(1968) 627-632. 